\title{
The hare hugs the rabbit. He is white ... Who is white? Pronominal anaphora in Russian ${ }^{1}$
}

\author{
Natalia Gagarina \\ Centre for General Linguistics, Typology and Universals Research (ZAS) \\ Berlin, Germany
}

This paper investigates the production and comprehension of intrasentential anaphoric pronominal reference in Russian. In particular, it examines the elicited imitation and comprehension of three anaphoric pronouns in subject position personal $3^{\text {rd }}$ singular masculine, demonstrative and zero - in one hundred and eighty monolingual Russian-speaking children and twenty adults. The three types of pronouns were designed to have an antecedent in the preceding sentence containing a verb and two arguments. These antecedents differ in their syntactical role and animacy. The sentence position, agentivity and topicality remained constant. The sentences with (in)animate subjects and objects constituted the following four 'conditions': two sentences with a subject and an object being either animate or inanimate and two sentences with a subject and an object exhibiting a diverse (in)animacy. Regarding the resolution of the anaphoric pronouns the similarity principle (or feature-concord rule) and its possible violations were tested. This principle suggests that an anaphoric pronoun is most likely resolved to the antecedent with a maximum of similar characteristics or features and it primarily governs the assignment of an antecedent to anaphoric pronouns in subject position in the absence of the violating conditions. Results show the influence of this rule on the anaphora resolution process increasing with age, on the one hand, and the development of the impact of animacy, syntactic role and the type of anaphoric pronouns that violate the feature-concord rule, on the other.

1 This study was performed in the tight cooperation with Dagmar Bittner, Milena Kuehnast and Insa Gülzow (see the respective papers in this volume). The design, material and conception of the experiments is the result of the joint work of all the project participants and their long-lasting and heated debates. My special thanks go to Elena Limbach for the transcription and coding of the data from Russian and to Inna Gridina for her assistance in the experiments. 


\section{Introduction}

Strangely, the studies on anaphoric pronominal reference and on verbal aspect show a notable resemblance.

The large body of literature on verbal aspect is full of dissimilarities in the terminology. Researchers struggle with the outsized variation that defines the notions of lexical, grammatical, situational aspect and so forth in diverse ways, and note that "[w]hile a detailed systematization of approaches is still lacking, the theoretical literature in this field is still growing ... there is no land in sight ..." (Sasse 2001: 2).

The large body of literature on anaphoric reference seems to accept the definition of anaphora (henceforth, I will speak about the pronominal anaphora only) and shows no general confusion in the concept of pronominal reference. Researchers agree that generally, the term anaphora embraces the co-referential relationship between text (discourse) items (cf. Bussmann 1996), and that anaphora resolution mechanisms disambiguate the pronominal reference, i.e. seek for the best-fitting and most proper antecedent of the anaphoric pronouns. The studies scrutinise this within- and cross-sentential relationship in the different types of discourses and different types of languages, e.g. artificial and natural. Yet, 'there is no land in sight' as far as the understanding of the rules and mechanisms governing the assignment of an antecedent to the pronominal anaphora, the factors governing these rules and their overall hierarchy and correlation is concerned. The overview of the most recent and the most prominent theories that differ in their salience ranking of the antecedents of the pronominal anaphora (modified ZAS-P2 proposal 2007) below seems to support the 'no land in sight' claim:

i. Classical Centering theory (Brennan et al. 1987; Walker et al. 1989; Grosz et al. 1995):

subject $<$ parallelism $<$ [semantic inferences $]^{2}$

ii. Functional Centering theory (Strube \& Hahn 1999):

discourse-old $<$ [semantic inferences] $<$ discourse-new $<$ parallelis

iii. Functional Sentence Perspective or Topic Focus Articulation (Adamec 1966, Daneš 1974, Hajičova 1974, Hajicova et al. 1993):

[semantic inferences] < parallelism < focus (new) $<$ topic (old)

iv. Integrated Model of anaphora resolution (Mitkov 2002):

[semantic parallelism] < syntactic parallelism < subject

v. Pragmatic Accounts (cf. Burzio 1996; Levinson 2000; Huang 2000):

topic (old) $<$ subject $<$ object

2 The understanding of the notion of semantic inferences may be different in the mentioned accounts. 
Thus, the Classical Centering Theory and the Integrated Model make contradictory predictions for the referent of her in sentences like (1) for Russian. Classical Centering goes for the subject preference, thus her refers to Maria, while the Integrated Model ranks syntactic parallelism as the highest resolution mechanism, thus her should be resolved into the direct object of the previous sentence, the daughter:

(1) Mama kormila doch'. Papa nezhno pogladil jejo

mother feed-ipf:past:sg:fem daughter-acc. father affectionately stroke-pf:past:sg:fem her 'The mother was feeding the daughter. The father affectionately stroke her'

So, bearing in mind these considerations and applying Sasse's (2001) statement to the scope of anaphora research, that "a detailed systematization of approaches is still lacking, the theoretical literature in this field is still growing", I aim at scrutinizing in this article only one particular issue regarding Russian-speaking children and adults. This very issue concerns the production and comprehension of intrasentential anaphoric $3^{\text {rd }}$ singular personal, proximate demonstrative masculine and zero pronouns in subject position (parallel SVO structures in the antecedent and anaphoric sentences) in sentences like (2a) to (2c), and will be highlighted in part 1.2. below:

(2) a Lev i zajac-horoshije staryje druz'ja. Lev obnimajet zajca. On smejotsja.

lion and hare good old friends. lion hug-ipf:pres:3s hare-acc. he laugh-ipf:pres:3s

'The lion and the hare are good old friends. The lion is hugging the hare. He is laughing.'

b Tigr i medved' - horoshije staryje druz'ja. Tigr obnimajet medved'a. Etot smejotsja. ${ }^{3}$ tiger and bear good old friends. tiger hug-ipf:pres:3s bear-acc. this laugh-ipf:pres:3s 'The tiger and the bear are good old friends. The tiger is hugging the bear. This is laughing.'

c Kot i lis - horoshije staryje druz'ja. Kot obnimajet lisa. Ø smejotsja. cat and fox good old friends. cat hug-ipf:pres:3s fox-acc. Ø laugh-ipf:pres:3s 'The cat and the fox are good old friends. The cat is hugging the fox. Ø is laughing.'

\subsection{Anaphoric reference in language acquisition}

The process of anaphora resolution requires inferences in order to determine an appropriate antecedent. The development of rules governing this process as well as the acquisition of the pronominal reference in children was one of the acquisitionists' main interests in the middle of the seventies and eighties. Experimental studies on production and comprehension as well as longitudinal studies showed

3 The sentences in $2 \mathrm{~b}$ and $2 \mathrm{c}$ are somewhat grammatically odd. 
controversies with respect to the age at which children acquire/use pronominal reference, and with respect to its functions and form (cf. Kail 1976, Wykes 1981, for more references see ZAS-P2 proposal, 2007). Furthermore these studies provide rather diverse evidence of the anaphora resolution mechanisms children employ and the interaction of regularities within these mechanisms. I will mainly address these studies, the overwhelming majority of which investigate the English-speaking populations; studies on Russian will be discussed at the end of this section.

The early experimental studies on the resolution of anaphora in children that children at the age of five use gender and number information in the anaphora resolution process (see ZAS-P2 proposal 2007). Wykes (1981) in his act-out comprehension experiments corroborated these results for sentences containing one anaphoric pronoun. Contradictory evidence was obtained in comprehension experiments with four year-old French-speaking children by Kail (1976), who found that children prefer the subject or agent as the antecedent, even despite the clear parallelism in gender between the object and pronominal anaphora. This preference for the antecedent with a similar syntactic role as the anaphoric pronoun and for the subject/topic as the most likely antecedent (Wykes 1981) had been shown to have much more influence on children than on adults and was explained as a child-specific resolution strategy. However, the same type of favourisation had been shown to be used by adults and was called parallelism in the 'adult' resolution theories. It is ranked as the highest resolution mechanism, at least in some resolution theories (Mitkov 2002), thus the child-specific resolution strategy may be called into question. In the experiments with the additional conditions, children were shown to exhibit difficulties in the selection of a proper antecedent (Wykes 1981). Two accounts for the problems with anaphora resolution discussed in the study deal with children's limited processing and inferential capacities and with resolution strategies different from those adults use.

Longitudinal and narrative data also provide miscellaneous evidence on the use of anaphoric reference in Russian as compared with English, German, French. On the one hand, Karmiloff-Smith's (1981) and Hickmann's (2003) investigations of narratives in English and French have shown that children use definite NPs and pronouns in primarily deictic function up to the age of approx. $6 ; 0$. On the other hand, recent analyses of the narratives of the Russian- and German-speaking monolingual children showed that already at age $3 ; 6$, they are able to use pronouns anaphorically and not only deictically, and that by this age children produce coherent and cohesive discourse (Gülzow and Gagarina, this volume). Additionally, longitudinal studies on German, e.g. Bittner (2002, 2007), provide evidence that already at the age of 2;2, German-speaking children show a functional division between the demonstrative pronouns das, der, die and den: das is used primary deictically while der, die and den are primarily 
anaphoric. Anaphoric demonstrative pronouns and full DP are used functionally distinct from the onset of their production. The former are used to maintain the conversation/topic and the latter are used to signal a topic shift or a contrast (cf. Bamberg 1987 for German, Hickmann et al. 1995 for French). Longitudinal studies on Russian reveal anaphoric uses of demonstrative, personal, and zero pronouns by the age of 2;6 and 3;0 by at least four children (e.g. Dobrova 2003, Gagarina 2006). Considering the successful every-day communication between children and their caretakers and the results of the previous observations, one may predict that core anaphora resolution mechanisms should have been acquired by the age of three, the age by which children acquire the basic morphological rules of their mother tongue, have the competence of a perspectiveshifting skill (Ricard et al. 1999) and make no errors in the reverse pronoun use (Dale and Crain-Toreson 1993).

As far as the salience hierarchy of the antecedents is concerned, longitudinal and experimental studies on pronominal reference acquisition as well as narrative studies rank antecedents differently and offer multiple scenarios of acquisition sequences of the salience criteria. On the one hand, Karmiloff-Smith (1981), Bamberg (1987) argue that children use thematic subject strategy in the production of narrative texts favouring subject or topic as the antecedents of pronouns. On the other hand, it is proposed that animacy plays a crucial role young children's pronoun understanding. Early sensitivity to animacy is found in studies that show early perceptive and categorical differentiation between animate and inanimate entities (Poulin-Dubois et al. 1996, Golinkoff-Smith et al. 1984). Generally, although postulating the high rank of the subject feature of an antecedent, researchers also include animacy and agentivity into the set of substantial/competing criteria defining the salience of the antecedent of the pronominal anaphora. These features define the syntactic and semantic roles, this distinction is not necessarily acquired or present in early children's grammars.

To summarise, a contradictory picture emerges from the overview of the research on anaphoric pronominal reference in children. On the one hand, studies report early abilities to resolve anaphoric pronouns onto the prominent subjects. On the other hand, the acquisitionists point to the children's early sensitivity to animateness. Furthermore, although children seem to have problems with anaphoric uses in discourse as late as the age of six, and seem to have problems with anaphora disambiguation when they have to draw additional inference and have more than one anaphoric pronoun to be disambiguated, the children develop their own strategies in order to manage anaphora resolution.

In view of the results of both theories on anaphora resolution in natural languages and from acquisition studies of anaphoric reference, the present study aims at establishing regularities which children follow in the resolution of intrasentential anaphora in 'simple' settings - the first sentence: two competing ante- 
cedents, subject and object, varying only in animacy; the following sentence anaphoric pronominal reference in subject position.

The structure of the article is as follows: the following part gives a very brief and schematised overview of the pronominal (anaphoric) reference in Russian. The next part describes and explains the chosen methods and procedures in detail. The two subsequent parts present hypotheses and results on comprehension and elicited imitation respectively. The conclusion finishes the paper.

\subsection{The system of pronominal reference in target Russian}

Russian is a morphologically rich language with the word order governed by the thema/rhema reasoning, i.e. old-new information sequence. The pronominal system includes 9 groups of pronouns (as specified in Švedova et al. 1980, Rosenthal et al. 1991, cf. Isačenko 1968, only 5 groups). For the purpose of the present study which explores the disambiguation strategies of personal, demonstrative and zero pronouns, I will concentrate in what follows on the description of these three types only. Personal pronouns are distributed between two numbers and three persons and are marked for six cases as shown in Table 1.

Table 1: $3^{\text {rd }}$ person pronouns in Russian

\begin{tabular}{llll}
\hline Person & Singular & Plural & Cases \\
\hline & & & 1. nominative \\
& He On & 2. genitive \\
& She Ona & They Oni & 3. dative \\
& It Ono & & 4. accusative \\
& & 5. instrumental \\
& & 6. locativ \\
\hline
\end{tabular}

As far as anaphoric use is concerned, masculine, feminine, and neuter $3^{\text {rd }}$ person singular pronouns may refer to both animate and inanimate antecedents, and the anaphoric uses may be said not to be constrained as it is the case with demonstratives. Generally, personal pronouns are considered to be the most 'neutral means of indicating continuity of reference across a sentence boundary'(Kresin 1998: 424).

Demonstrative pronouns form two groups, proximate and distal, which in turn contain pronouns in three genders in the singular: masculine, feminine, and neutral, as well as plural forms marked for six cases, table 2: 
Table 2: Masculine demonstrative pronouns in Russian

\begin{tabular}{|c|c|c|c|}
\hline Person & Proximate & Distal & Cases \\
\hline Masculine & This etot & That tot & $\begin{array}{l}\text { 1. nominative } \\
\text { 2. genitive } \\
\text { 3. dative } \\
\text { 4. accusative } \\
\text { 5. instrumental } \\
\text { 6. locative }\end{array}$ \\
\hline
\end{tabular}

The anaphoric use of these types of pronouns is strongly connected with the deictic function and is restricted to specific, contrastive contexts (Paducheva 1985, Krasavina 2004) with two or more antecedents, where the speakers 'wishes to distinguish between two potential referents' (Kresin 1998: 424 about distal tot, but this is also true for the proximate etot). In adult Russian the proximate forms are treated as unmarked and dominant in comparison with the distal forms; in the children's longitudinal naturalistic data these forms occur earlier than their distal counterparts. Considering all the above-mentioned reasons, it is the proximate forms that have been chosen for the experiment.

Russian is arguably considered a weak pro-drop language. Franks (1995) considers Russian pro-drop features to be of the Chinese "non-local" specification type (:303) and arguers that 'Russian really is not morphologically uniform, hence not pro-drop in the sense that null subjects are not licensed' (1995:301, cf. Geist 2006 - on the non pro-drop character of Russian). Traditional Russian grammars point to the six categories of sentences, the so-called one-component sentences that don't have an overt grammatical subject (Rosental' et al. 1991). These sentences are given in (3):

(3) a. (I) Pishu knigu write-ipf:pres:1s book-acc:sg

'I'm writing a/the book'

b. (They) Mame dali (dadut) knigu. mother-dat:sg:book give-pf:past:sg:fem (give-pf:pres:3sg) book-acc:sg 'The mother will get the book'

c. (You) Pishesh' knigu, a mysli putajustja.

Write-ipf:pres:2s book-acc:sg, and the thoughts confuse-ipf:pres:3g

'When one writs the book, the thoughts are confused'

d. (It) Temneet.

Impersonal becoming-dark-ipf:pres:3s

'It's becoming dark' 
e. Prinjat' knigu k pechati.

Accept-inf book:acc:sg to print-dat:sg

'Accept the book for printing!'

f. Noch'. Ulica. Fonar'. Apteka (A. Blok's poem)

Night. Street. Lantern. Pharmacy.'

So, zero (pro)nominal subjects are more frequently used in sentences in which the predicates are marked for person-number; these predicates are imperfective verbs in the present and perfectives in the future (for the regularity of subject omissions in Russian see Geldbach 1999, Švedova et al. 1980, Franks 1995). Animacy is manifested in the accusative case marking of the masculine nouns of the second declension. Accusative of inanimate nouns is equal to nominative, like stol 'table-acc=nom', whereas accusative of animate nouns is equal to genitive, like tigra 'tiger-gen=nom'.

\section{Method}

\subsection{Participants}

180 monolingual children from middle-class families of St. Petersburg took part in the experiment. As a control group, 21 adults were tested. The distribution of subjects across groups is given in Table 3 .

Table 3: Participants and database.

\begin{tabular}{|c|c|c|c|}
\hline Group ID & Age & N. of subjects per group & N. of subjects per year \\
\hline 9 & $18-23,40,65$ & 21 (adults) & \\
\hline 1 & $2 ; 0-2 ; 11$ & 20 & 20 \\
\hline 2 & $3 ; 0-3 ; 5$ & 25 & 52 \\
\hline 3 & $3 ; 6-3 ; 11$ & 27 & \\
\hline 4 & $4 ; 0-4 ; 5$ & 26 & 66 \\
\hline 5 & $4 ; 6-4 ; 11$ & 42 & \\
\hline 6 & $5 ; 0-5 ; 5$ & 26 & 40 (with 3 children at \\
\hline \multirow[t]{2}{*}{7} & $5 ; 6-5 ; 11$ & $14 \int$ & $6 ; 0)$ \\
\hline & & 180 (children) & \\
\hline
\end{tabular}

Subjects were excluded from the calculations if they didn't react to at least half of the stimuli sentences and didn't also participate in the comprehension task at least half of the time. 


\subsection{Design of the study}

The data were collected in the experimental procedure that can be called "fourin-one"; the four combined parts representing the elicited imitation (sentence repetition) task, with each repeated-sentence followed by a comprehension question and two elicited narratives. Narratives were obtained on the basis of two picture stories, one of which is Hickman's (2003) cat-story. The other is a foxstory, designed specifically for the project (painter J. Mühring), in which all three protagonists belong to the same gender and differ only in animacy (see appendix 2$)^{4}$. This very design of the experiment was chosen since it doesn't interfere with the three experimental techniques used in the experiment, because it provides us with comprehension data and two types of production data simultaneously, and because it allows the combined comparison of different data modes. The goal of the elicited imitation experiment was to check whether and in what conditions do children correct/change grammatically odd sentences, containing an anaphor with an antecedent in the previous sentence.

In particular, the elicited imitation task and the comprehension task were performed in the following way: children had to listen to 6 situations (an act out design), repeat 6 stimuli sentences terminating each of these situations, and disambiguate the pronominal reference by answering the who-question, then tell two stories on the basis of six pictures each and deal again with the remaining 6 situations. In the experiment, children hear one of the two fellows with different types of (in)animate subjects and objects to avoid the influence of the specific types of protagonists (the list of protagonists is given in appendix 1). Furthermore, the verbs were controlled in order to avoid a too direct semantic inference on the resolution process. The fellow's sentences were randomised and presented to children basically in two orders. As warming up and pausing, the language comprehension test, checking the level of understanding of verbs and prepositions was presented to the children (Siegmüller and Kautchke 2006). An example of one situation from fellow one type is given below:

4 The analyses of narratives is beyond the scope of this paper, but since they were incorporated into the experiment, I found it necessary to give a short note on them. 
A narrator - the first experimenter - holds a white bear and a white ball in his hands and acts out the story she pronounces:

Look, here is a bear and here is a ball. The bear likes to play football. The ball is in front of the bear. The bear is kicking the ball. $\underline{\mathrm{He}}$ is white. (The last, stimuli sentence that the child has to repeat; was whispered)

A distracted puppet - second experimenter - asks:

Oh, what did she say? Repeat.

Child: He is white. [child's production: sentence imitation]

A distracted puppet - second experimenter - asks:

Who is white?

Child: $\quad$ The ball.

[child's comprehension: answer to the wh-question]

In total, twelve situations result from four $\times$ three conditions. The four conditions represent the combination of (in)animacy of subjects and objects, and the group of the three conditions corresponds to the type of the pronominal reference in the stimuli sentence, i.e. zero, personal or demonstrative pronouns (see Table 4 below).

Table 4: Design of twelve situations: types of sentences and pronouns

\begin{tabular}{|c|c|c|c|}
\hline Type of sentence & Type of subject & Type of object & Type of pronoun \\
\hline A & Animate Subject & Animate Object & $\begin{array}{l}\text { 1. Personal } \\
\text { 2. Demonstrative } \\
\text { 3. Zero }\end{array}$ \\
\hline B & Inanimate Subject & Animate Object & $\begin{array}{l}\text { 1. Personal } \\
\text { 2. Demonstrative } \\
\text { 3. Zero }\end{array}$ \\
\hline $\mathrm{C}$ & Inanimate Subject & Inanimate Object & $\begin{array}{l}\text { 1. Personal } \\
\text { 2. Demonstrative } \\
\text { 3. Zero }\end{array}$ \\
\hline $\mathrm{D}$ & Animate Subject & Inanimate Object & $\begin{array}{l}\text { 1. Personal } \\
\text { 2. Demonstrative } \\
\text { 3. Zero }\end{array}$ \\
\hline
\end{tabular}

The four types of potential antecedents form a linear continuum with the salience decreasing towards the right edge: animate $\mathrm{S}>$ inanimate $\mathrm{S}>$ animate $\mathrm{O}>$ inanimate $\mathrm{O}$. These four types of sentences may build a somewhat different continuum of hierarchal salience if one treats the object and subject in tandem. This continuum may have two possible orders, depending on the underlying condition which defines salience. If one assumes the absolute prominence of subjects 
irrespective of animacy (in our case, all subjects are agents ${ }^{5}$, topics, and are firstpositioned in the sentence) and presupposes that the subject/agent rule is the basic rule children obey in their resolution strategy from age $2 ; 6$, the following continuum with the salience decreasing top-down may be proposed (the most prominent antecedents within a sentence type are marked in bold):

\begin{tabular}{|c|c|c|}
\hline (4) & +animate S // & -animate $\mathrm{O}$ \\
\hline & tanimate S // & tanimate $\mathrm{O}$ \\
\hline & -animate S // & -animate $\mathrm{O}$ \\
\hline & -animate S // & +animate $\mathrm{O}$ \\
\hline
\end{tabular}

Assuming the interaction of salience of the two main verb arguments, the salience of first-positioned subject is highest in condition $\mathrm{D}$, in which the object is inanimate, and it is lowest (but still higher than the object) in condition $\mathrm{B}$, in which the object is animate.

If one considers animacy as a feature that is able to violate or even override the subject's prominence, then the continuum exhibits the following order with the salience decreasing top-down (the most prominent antecedents within a sentence type are marked in bold):

$\begin{array}{llll}\text { +animate S } & / / & \text {-animate } \mathrm{O} & \rightarrow \mathrm{D} \\ \text {-animate S } & / / & \text { +animate } \mathrm{O} & \rightarrow \mathrm{B} \\ \text { +animate S } & / / & \text { +animate } \mathrm{O} & \rightarrow \mathrm{A} \\ \text {-animate S } & / / & \text {-animate } \mathrm{O} & \rightarrow \mathrm{C}\end{array}$

Again the subject is the most preferred candidate in condition $\mathrm{D}$, followed by the animate object as the next prominent antecedent since it occurs in a sentence with an inanimate subject, so we expect the smaller children to prefer the object in condition B, since the animacy should play a more important role in their choice.

\subsection{The choice of experimental technique and age}

The elicited imitation (sentence imitation) task as an experimental technique to control pronoun production was chosen due to several reasons. Firstly, we started from the assumption that "when children are asked to imitate a sentence, they often make changes ... the way THEY think it should be" (O'Grady 2005), so by presenting non-target sentences to children, we expected them to correct these sentences in a systematic way. Secondly, other researchers had already

5 Note, that in sentences with a null copula (and s-predicates), like On sinij 'He (is) blue' the subject are not the 'real' agents. 
successfully used this technique; e.g. Lust (1981), who asked 2;6 to 3;6 year olds to repeat sentences like: Because Sam was thirsty, Sam drank some soda and Because he was thirsty, Sam drank some soda. Children corrected the first and the second sentences in the following way: Because Sam was thirsty, he drank some soda and Because Sam was thirsty, he drank some soda, respectively. More recently, Ambridge and Pine (2006) effectively used elicited imitation to examine the agreement/tense omission model "for precise control of the target utterance with respect to the pronoun subject" (Ambridge and Pine 2006:884). Thirdly, this technique seemed to us the most successful way to make young children produce the three types of pronouns we intended to investigate.

We started testing children from the age of two and a half. The reasons for starting with this age-group were the following. Two and a half is the lowest border allowing the performance of such a type of experiments: our longitudinal data and results of previous research showed that children by this age can be said to have acquired pronouns basically that means that no reverse use like,

"I'll carry you for 'YOU carry ME'

Lift you up and you can see the window for 'Lift ME up and I can see the window"' (cited after O'Grady 2005:76)

is found (cf. at the age of 18 months approx. 50\% of pronominal reference is reverse: Dale and Crain-Toreson (1993)). Furthermore, by this age children have acquired the so-called the perspective-shifting skill (Ricard et al. 1999) and they reach the cognitive ability to follow the (linguistic) task and change its linguistic components if necessary.

\section{Study one - comsprehension}

\subsection{Assignment of antecedents - predictions}

If the interpretation of the results in the previously reviewed studies is true, the following hypotheses stemming from the theories discussed and from the results of the previous studies, can be proposed:

1. The similarity principle primarily governs the assignment of a antecedent to anaphoric pronouns in subject position in the absence of the violating conditions. The violating conditions, like, for example, speakers' age and language-/pronoun-specific factors, may weaken the controlling supremacy of this principle. 
The similarity principle or feature-concord rule postulates that an anaphoric pronoun is most likely resolved to the antecedent with the maximum of similar characteristics or features. In our case these features include (but generally may not be restricted to) the syntactic role, agentivity, sentence position and topicality. ${ }^{6}$ The similarity principle strongly resembles parallelism assumed in anaphora resolution theories (cf. Mitkov 2002); it differs from the latter in the number of features that co-refer an antecedent and a anaphor. Parallelism postulates the anaphora resolution into the antecedent with the same syntactical role and sentence position, similarity rule extends the number of features to topicality, agentivity, semantic parallelism, etc. In the present study the sentence position is fused with syntactic role and agentivity, since subjects are predominantly agents and always have the sentence initial position. In contrast, the objects are recipients and occupy the sentence final position. The separation of these features is the matter of the future experiment.

The three violating conditions and their essentials: first, under speakers' age influence I understand constrains in young children on processing and referential capacities, e.g. the recency of mentioning effect (cf. Wykes 1981), and incompleteness in the acquisition of notions of the syntactic role. Second, language-universal constrains include the feature animacy, the addition of which to the antecedent can make it the most attractive candidate for the resolution despite the similarity principle. Third, language-specific factors which may include functional restriction on or language-specific preference of the antecedents for certain pronouns, like for example der in German, have been shown to be more likely resolved to the object NP of the previous clause or sentence (Bosch, Katz, and Umbach 2007).

Prediction one (without violating factors) would mean that, in our case, children at all ages would tend to resolve all pronominal anaphora of the experiment onto subjects irrespectively of their animacy. The following factors (with the degree of influence decreasing top down) are anticipated to violate this rule:

2. The similarity rule is age-sensitive, i.e. the effect of this rule is weaker in the youngest children who may not yet recognize all similar features of the anaphora and the antecedent and may show higher sensitivity to another features, in our case - animacy. Hence, in condition B the most probable antecedent would be an animate object in youngest children (also due to the recency of mentioning)

6 According to the topic-similarity the anaphoric pronouns he and zero should refer to the first protagonist, which is a topic. 
3. The similarity rule is animacy-sensitive, i.e. the effect of the rule may be violated in the non-prototypical combination 'inanimate subject - animate object' (condition B) and this is especially true for young children, who may rank animacy higher as the feature-similarity rule

4. The similarity rule is pronoun-sensitive, i.e. demonstrative pronouns as structurally more complex anaphora may be resolved into the least salient referents - inanimate objects (and this is especially true for condition B), since in the resolution process these referents take priority over the antecedents displaying features maximally similar to the anaphora features. Moreover, language-specific constrains on the antecedent references of demonstratives are at play here - demonstratives are said to refer most typically to subordinate antecedents in non-subject syntactical role and to mark the topic-shift in discourse. ${ }^{7}$

The interaction of the similarity rule with the three violating conditions given above manifests in the fact that the number of choices of subjects as the antecedents of anaphoric pronouns will be lower in cases where these conditions are manifested most prominently, like young age and animacy of objects in tandem with inanimacy of subject (condition B). Since the target sentences always contain two possible antecedents with changing animacy features, the subject and the object, the effect of the subject rule is expected to be stronger in the Dcondition, where the antecedent subject is the most prominent, since it contains the features [+animate], [+agent], [combined with -animate object]. And consequently this effect is expected to be the weakest in B-condition, where the antecedent subject has the features [-animate], [+agent], [combined with +animate object]. The animacy influence on subject/agent effect is expected to be the most strong with the youngest children, who are more sensitive to animacy than their older siblings.

7 As noted above, the stimuli sentences contain three types of pronouns - personal, demonstrative and zero, with the two latter types of stimuli being not fully grammatical in Russian. The influence of a reversed mapping is expected to be stronger in these grammatically odd sentences. A reversed mapping constrains the relationship between anaphora and their antecedents in the way that structurally more complex anaphora are related to less salient referents and vice versa (Gundel et al. 1993; Ariel 2001), e.g. demonstrative pronouns should be more often resolved into objects, especially in condition $\mathrm{B}$ which contrasts an animate object and inanimate subject. However, the language-specific constraints on their referential functions violate this rule. 


\subsection{Assignment of antecedents - result}

The results are presented in three steps: I start with the general distributional picture of subject and object choices (Figure 1), move towards the choices of subjects and object within the sentence types (Figure 2), and finish with by adding the three pronoun types to the distribution picture (Figures 3, 4 and $4 \mathrm{a}-4 \mathrm{c}$ ).

The general choices of subjects given in Figure 1 is scrutinised in the next two figures which basically repeat figure one but with the columns divided horizontally into four parts according to the A, B, C, and D sentence types and then vertically - into three parts according to the three pronoun types: personal, demonstrative and zero. The purpose of this three-step delineable schema is to provide a smooth transition from a general into a detailed insight of the anaphora resolution in all twelve conditions and thus to facilitate the comprehension of the last graph in this part.

Figure 1 shows the distribution of $\mathrm{S}$ vs. $\mathrm{O}$ choices out of all choices of subjects and objects, given in percentages.

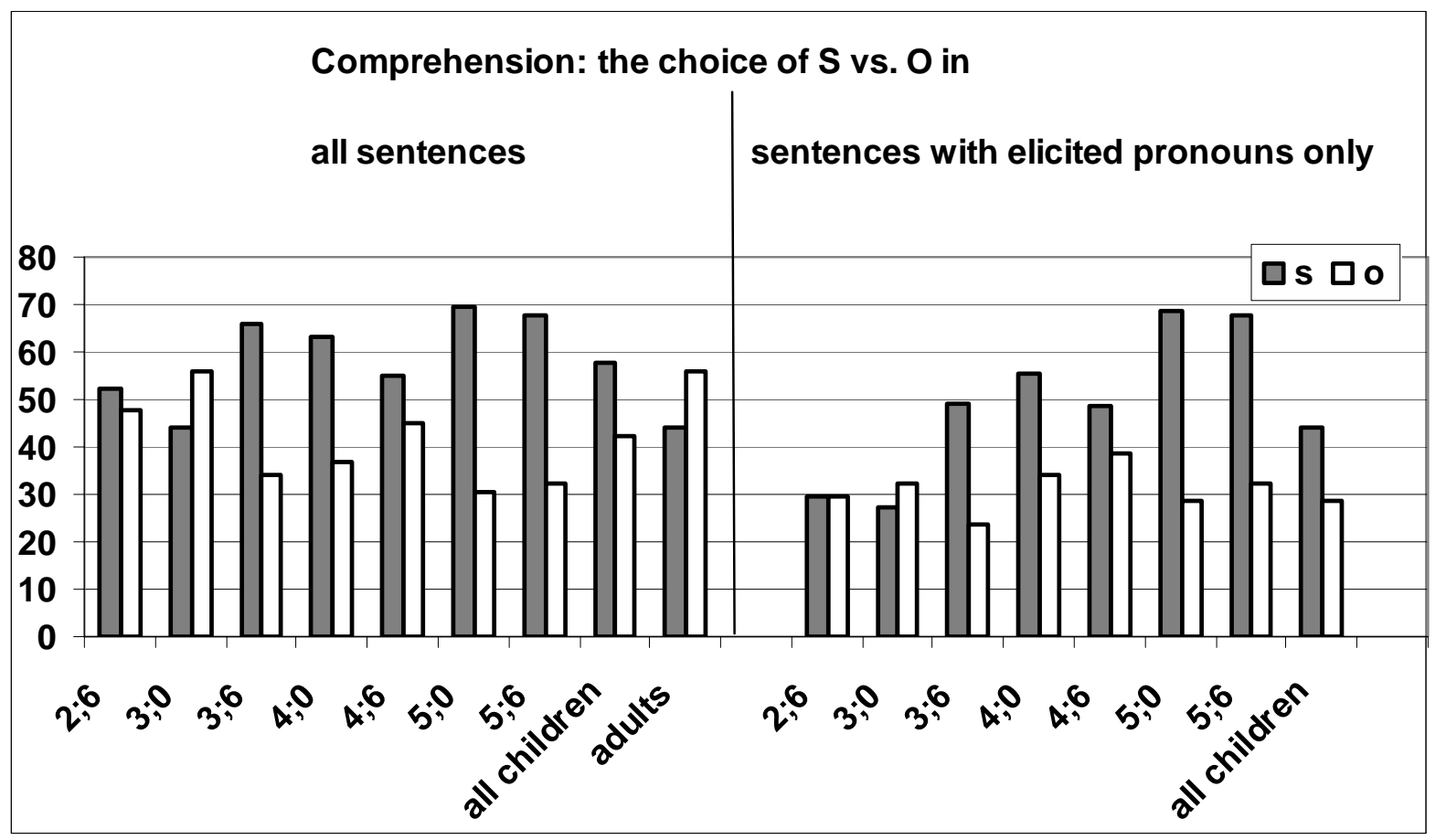

Figure 1: Resolution of anaphoric pronouns into subjects vs. objects in all data from Russian $^{8}$

The two parts of the figure mirror each other with one distinction: the left part includes all choices irrespectively of the successfulness of the participation in the sentence repetition task, while the right part is restricted only to the 'full participation in the experiment', i.e. children repeated pronouns in the first, elicited

8 All figures present percentages on the vertical axe, except for cases notified extra. 
imitation task, and have chosen either subject or object in the second, comprehension task. Since adults were not introduced to the elicited imitation task (in the pilot study all were imitating stimuli sentences without any changes) the respective columns in the left part are empty. There is no significant variation the correlation of subject vs. object choices between the two parts of this figure. The minor proportional dissimilarity between the corresponding values in the left and right part of this figure is obvious in the groups of 2;6 year old children, who equally choose subjects and objects when they repeated pronouns in comparison with the slight preference for subjects if choices in all sentences are counted. The clearly observable difference in the general amount of responses, which is lower in the right part, since not all children had successfully imitated pronoun sentences diminishes with age. All analyses of this section below are based on the right part, dealing with the data of children who fully participated in the experiment, i.e. successfully fulfilled the two tasks. The data of adults, which show a different bias in choices will be analysed separately. At this point one cannot help noting that adults seem to generally use the opposition/confrontation strategy, resisting to the anaphora resolution rules that rank the subject as the most probable and the most salient antecedent, and seeking a forgery in the anaphoric reference they have to resolve, thus naming on purpose the 'wrong' antecedent (see more detailed analyses below). The second possible explanation of the object preference is given when referring to the type of anaphora and their role in the continuity of reference representation in discourse.

The two younger groups differ from all older groups in that they do not prefer subjects over objects. The preference for subjects increases with age and reaches a significant difference at the two oldest groups (significantly higher when objects are inanimate). ${ }^{9}$

The next Figure 2 shows the distribution of subject vs. object choice divided into four sentence types. Such division provides an outlook onto the distribution of subject/object preferences within animacy and subjecthood combinations, which shows the most clear development in three age groups: three-, four-s, and five-year olds. These three age groups are marked in bold and by an oval and will be described in detail below. The 'intermediate' groups resemble the developmental curve within the three 'main' groups taken for the detailed description.

9 The statistical analyses for this study were mainly done by E. Andonova from the University of Bremen. The Chi-square results I obtained by myself. 


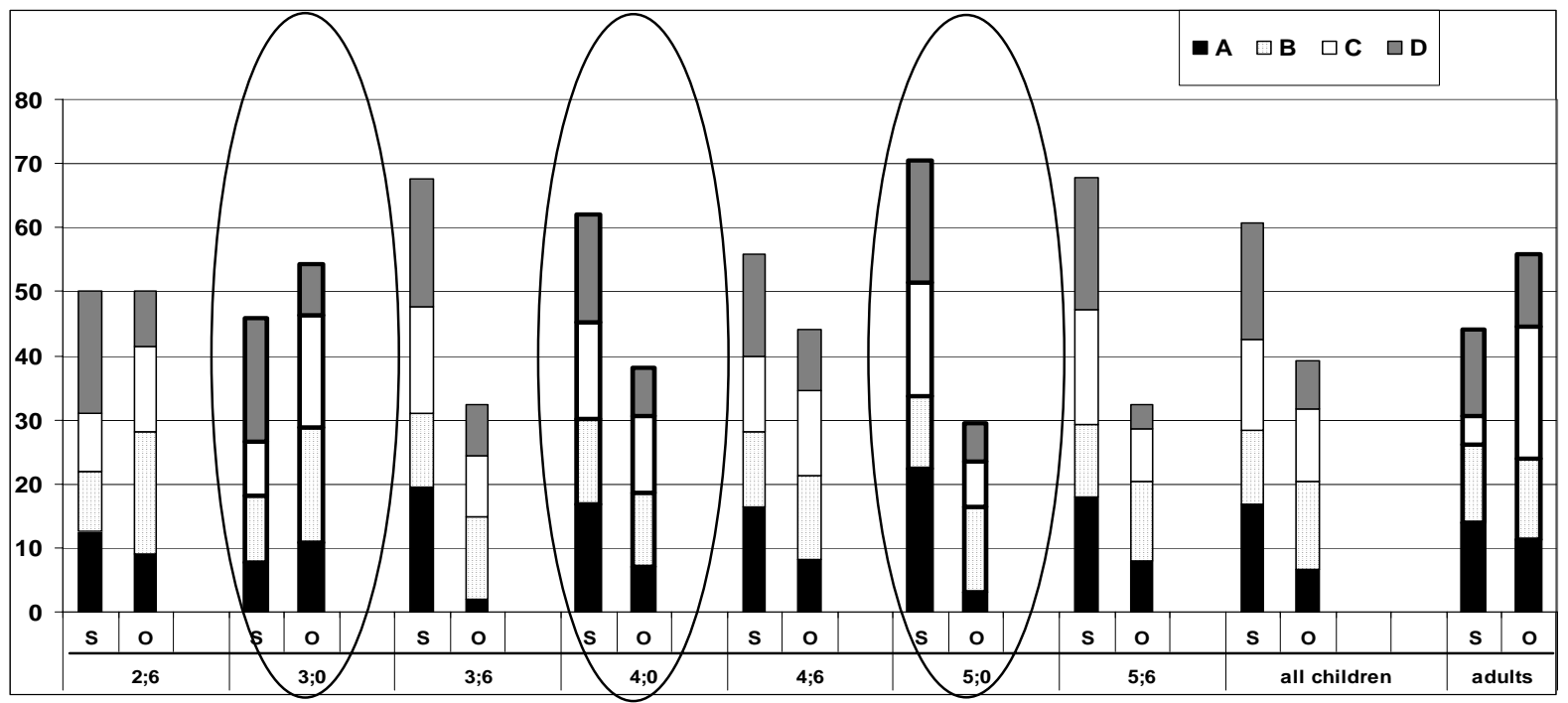

Figure 2: Resolution of anaphoric pronouns into subjects vs. objects across sentence types

First, consider condition D, the highest part of columns marked in dotted black, which shows constant increase of subject vs. decrease of object choices in this category - children learn to recognize the similarity rule and resolve anaphora into subject in the most prototypical constellation of verb arguments: animate subject/inanimate object. This bias towards subjects is even stronger if we summarize conditions $\mathrm{A}$ and $\mathrm{D}$, the two black parts of the columns, which exhibit the animate subjects. A significant main effect of animacy $(\mathrm{p}<0,0067)$ occurs at 4;00 and becomes even more significant with five year old children. Interestingly, these two conditions are the only conditions where adults slightly prefer subjects over objects (14\% vs. $11 \%$ in condition D and the same proportion in condition A), however the rate of their choices differ across the three pronoun types. But this small adults' subject preference is generally overridden by the highly significant preference for objects in condition $C(p<0,0017)$. It is this condition that 'compiles' the general object preference in adults data.

In condition $\mathrm{C}$, the youngest children behave similarly to the adults in that they prefer objects. Four and five year-olds exhibit a subject bias in this condition, and the degree of subject preference in the oldest group is highly significant $(p<0,0002)$. The same bias for subject is clearly seen in condition A in the two older groups: it is also significant for these groups $(p<0,0125)$. An interferential summary thus shows that in conditions where both a subject and an object are either animate or inanimate, children increasingly choose subjects, thus learning to differentiate syntactical roles in the anaphora resolution process and learning to obey the similarity rule (the ranking of animacy is lower as the ranking of a syntactic role). 
Second, consider condition B, the dotted white part of the column, where I predict the strongest violation of the similarity rule. In this condition no subject bias is found at all. However, the slight preponderance of objects is not significant thus, the distribution of choices between subjects and objects can be said to be at a chance level.

The split of subject vs. object preference which provides a more differentiated view regarding the types of imitated pronouns is given in Figures 3 and 4 below. For a better comprehension of the figures below recall explanation in 3.2. and imagine that each column of Figure 2 is vertically divided into three parts, representing the types of pronouns children repeated and adults heard (remember adults did not have the elicited imitation task).

Adults' data that are given separately in Figure 3 show the slight preference for subjects with personal pronouns and no preference for either subjects or objects with zero pronouns. With regard to demonstratives, adult resolve these into objects significantly more often across all conditions $(\mathrm{p}<0,001) .{ }^{10}$

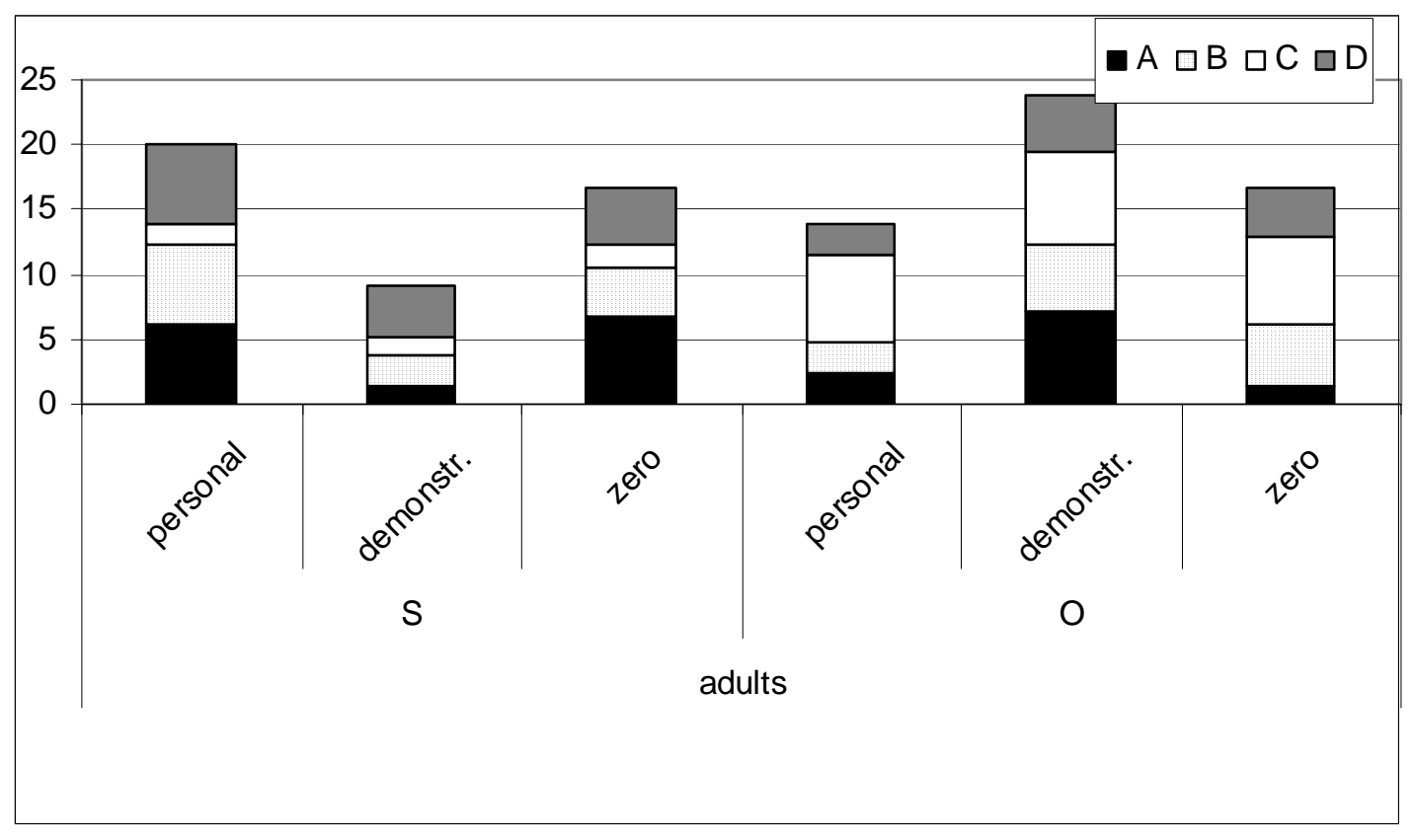

Figure 3: Resolution of anaphoric pronouns into subjects vs. objects in adult data from Russian

The more diverse representation of choices occurs across the sentence conditions A, B, C, and D (vertical division of the columns in Figure 2). Here, the preference $<$ subjects--personal pronouns $>$ is especially evident in conditions A

10 This corroborates the data for the distal pronouns: "when there are two potential referents with the same gender and number, tot is said to corefer to the most recent potential antecedent (Revzin 1973:123) or to a previous non-subject antecedent (Adamec 1988:170, Koktova 1992)' Kresin 1998:421, cf. Krasavina et al. 2007 
and $\mathrm{D}$ where the subjects are animate. The preference <subjects--zero pronouns $>$ is especially strong in condition A and less evident in condition D where the subjects are animate. No preference for subjects with demonstrative pronouns is observed.

The overall preference for objects with demonstratives is highly significant, $\mathrm{p}<0,001$. In condition $\mathrm{C}$, this preference seems to be 'pronoun-resistant', since it does not change at all neither for personal, nor for demonstrative or zero pronouns. In condition A, the same preference for objects is registered only for demonstratives, thus, probably evidencing the specific anaphoric functions of demonstratives in discourse.

Figure 4 below presents the same structure as Figure 3, yet for children. The same three most representative groups of children marked with an oval will be described. I first compare the first and the second columns in three age groups: these columns reflect the choices of subjects in sentences with personal and demonstrative pronouns and they both increase likewise towards the oldest group. If we contrast them to the third column which does not change across ages significantly, we will see that all three columns draw nearer to each other, thus showing only a slight impact of the pronoun types on the choice of the antecedents. The minor tendency for a subject preference in sentences with zero pronouns is not significant.

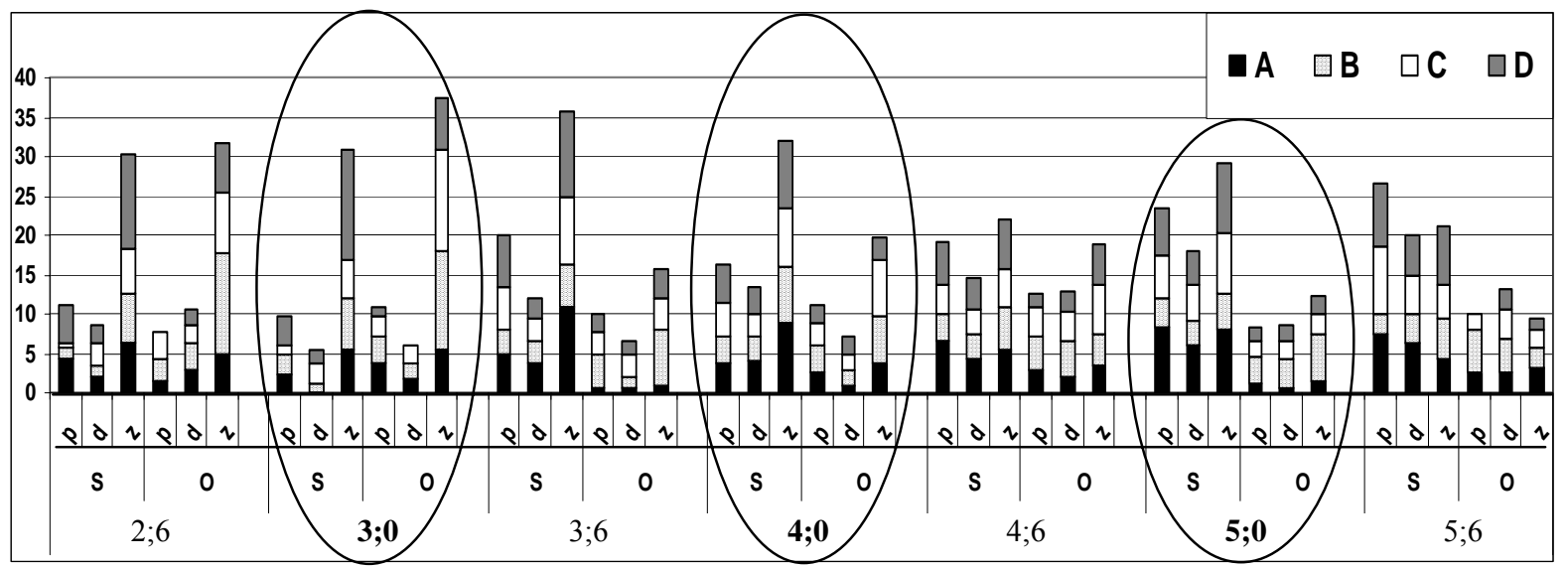

Figure 4: Resolution of anaphoric pronouns into subjects vs. objects in all data from Russian

The same tendency (of narrowing the scope of choices across three types of pronouns) in the selection of objects is observed in the last three columns in each age group. While the choice of objects does not change across ages in sentences with personal and demonstrative pronouns, it significantly decreases towards the older group in the zero pronoun sentences, $\mathrm{p}<0.0399$. 
Figures $4 \mathrm{a}$ to $4 \mathrm{c}$ are a somewhat more scrupulous representation of the relevant parts of Figure 4 and show in details the selection of subjects vs. objects across the three types of pronouns and the four conditions.

Figure $4 \mathrm{a}$ provides the overview of the subject vs. object choices after the elicited personal pronouns. In condition A, the preference of subjects over objects is at chance level by younger children and develops towards the significant difference towards the oldest children. In condition B, no significant developmental effects are attested and the choices of subject vs. objects stay at a chance level, yet the slight tendency for the animate objects is seen with the youngest children. Condition $\mathrm{C}$ replicates the developmental picture of condition $\mathrm{A}$ as far as subjects is concerned and shows no changes across ages in the choice of objects: they remain at the level below $5 \%$. In condition $\mathrm{D}$, the preponderance for subjects in all age groups is seen, this preponderance increases towards the older children.

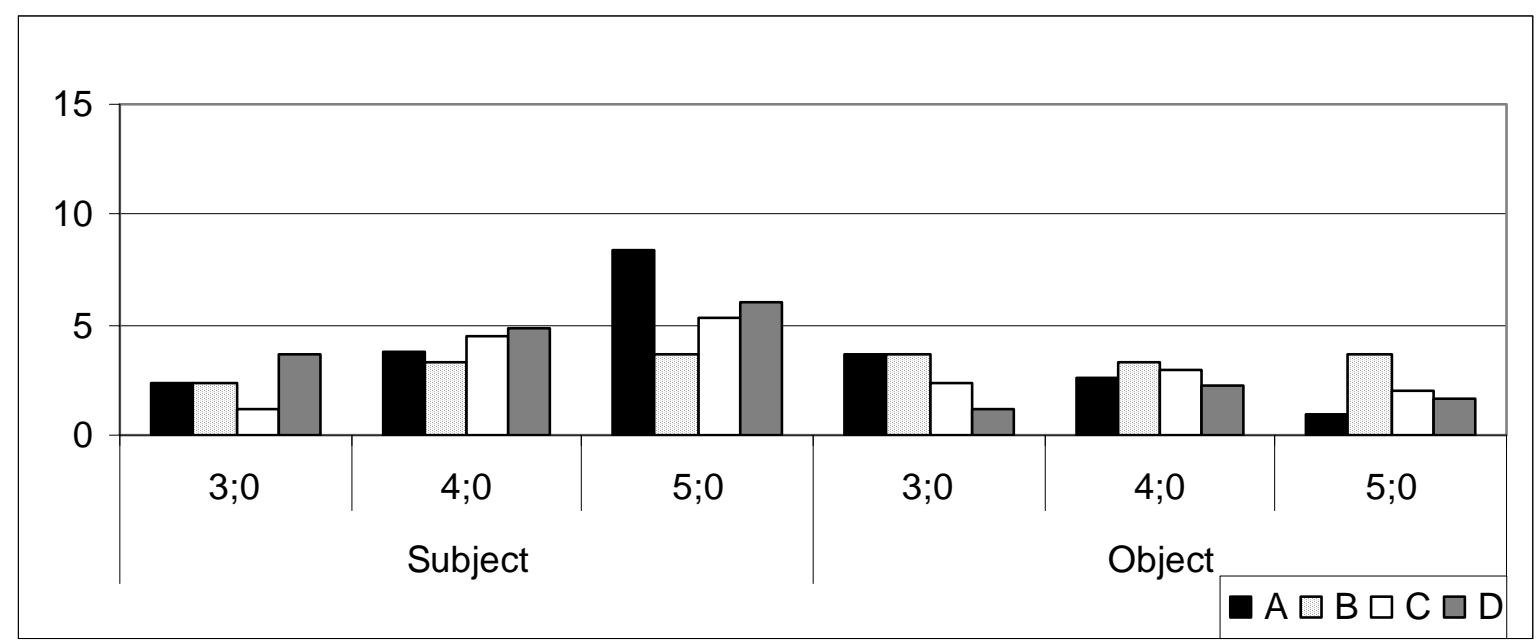

Figure 4a: Resolution of anaphoric pronouns into subjects vs. objects in all data from Russian: elicited personal pronouns

Figure $4 \mathrm{~b}$ provides the overview of the subject vs. object choices after the elicited demonstrative pronouns. This pronominal type that exhibits very specific anaphoric functions is underrepresented. Children frequently omit or substitute the demonstrative pronouns in the elicited imitation task. The most clear effect with this lower number of demonstratives' uses is the increase of the subjects preference towards the older children in all conditions except for condition B. This effect is most strongly manifested in condition A. 


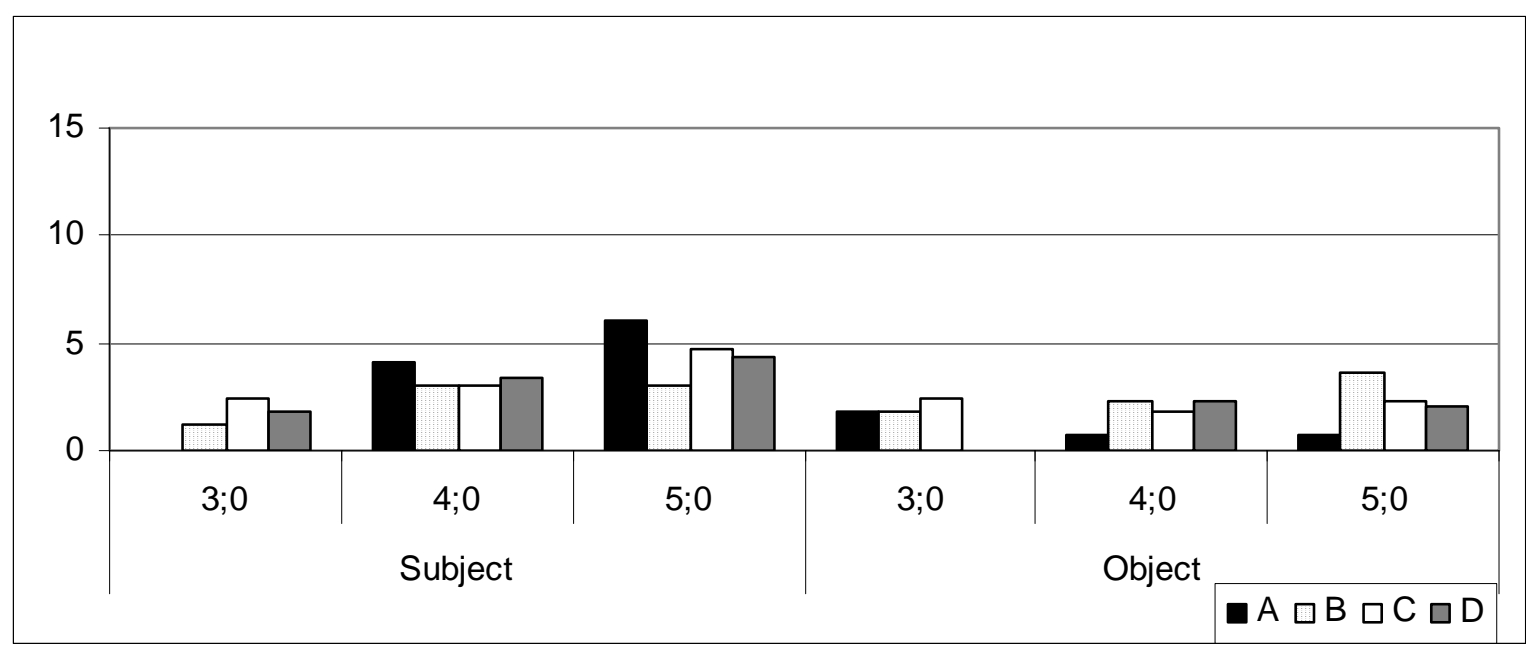

Figure 4b: Resolution of anaphoric pronouns into subjects vs. objects in all data from Russian: elicited demonstrative pronouns

Figure $4 \mathrm{c}$ provides the overview of the subject vs. object choices after the elicited zero pronouns. This type of the pronouns, i.e. omissions, is the most frequent in comparison with the two previous types. In condition $\mathrm{A}$, the slight increase of subject choices vs. the strong decrease of object choices towards the older group is observed. In condition B, no changes in the subject choices is observed vs. strong decrease of object choices towards the four-year-old children is seen (the number of object choices remains the same within the two oldest groups). Condition $\mathrm{C}$ remains condition $\mathrm{A}$ although the tendencies are manifested weaker. Finally, condition D show the decreasing tendencies in both subjects and objects choices, with the preference for subjects across all children.

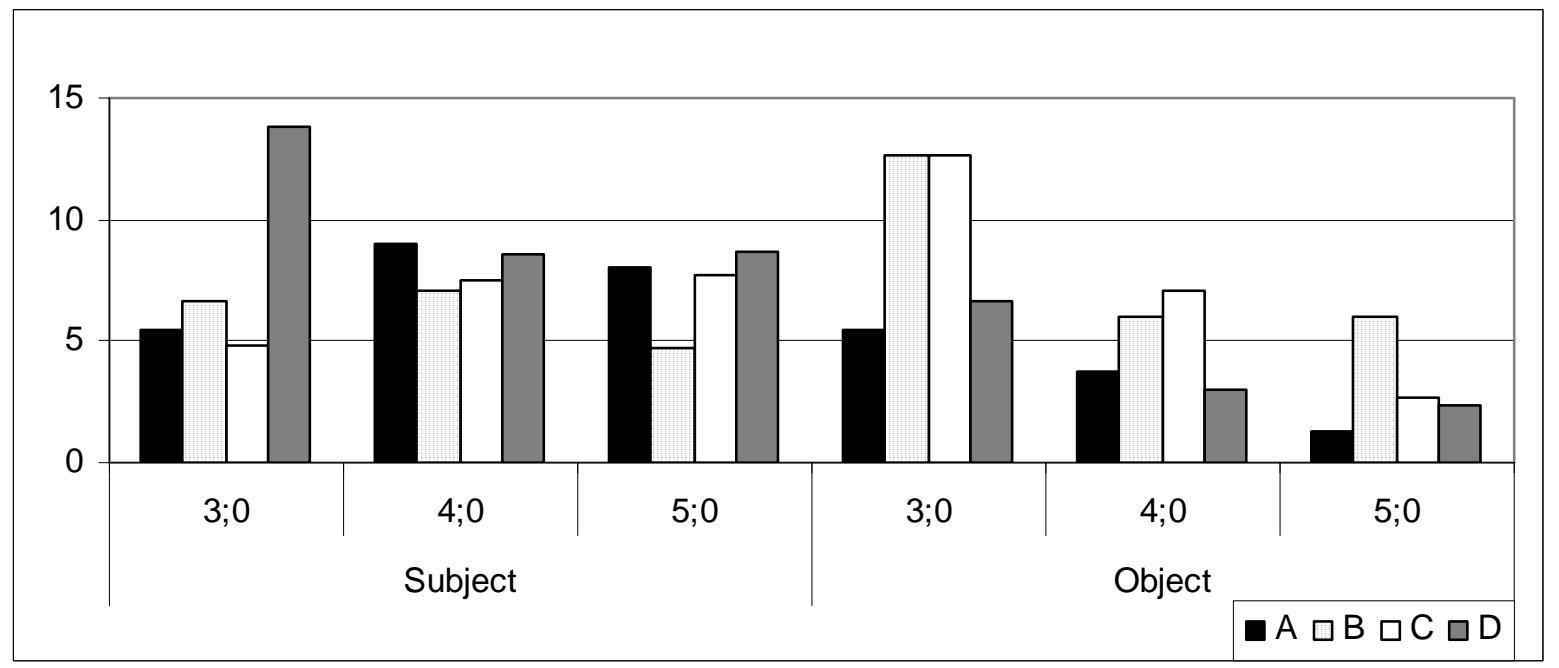

Figure 4c: Resolution of anaphoric pronouns into subjects vs. objects in all data from Russian: elicited zero pronouns 


\section{$4 \quad$ Study two - elicited imitation}

\subsection{Elicited imitation strategies - predictions}

To recapitulate briefly, children were asked to repeat stimuli sentences containing personal, demonstrative and zero anaphoric pronouns following the antecedent sentences which contained subjects and objects having the two variables +/animacy in crossed variations (see table 4). The predictions are the following:

1. Children will imitate the grammatically correct stimuli sentences with personal pronoun without any deviation from the stimuli. In case of any errors in these stimuli sentences - omissions and/or substitutions - they should occur in the prototypical condition B (the animate subjects and inanimate objects) where children will subjects as the anaphora referent. Omissions are expected to be generally more frequent with the younger children as with the older children (it is 'cognitively easier' to omit an item as to substitute an item and young children often omit pronominal subjects, see Gerken 1991 and Valian et al. 1996); no substitutions of personal pronouns with the demonstrative etot are expected

2. Systematic divergence to the stimuli is expected in the grammatically odd sentences with demonstrative and zero pronouns. This divergence can be divided into two categories:

(a) $<$ omission $>$ and (b) $<$ replacement $>$, the latter can be in its turn divided into $\left(b_{1}\right)<$ non-target to target replacement $>$ and $\left(b_{2}\right)<$ non-target to nontarget replacement $>$.

Taking into consideration that all situations were acted out in front of the children, sentences with the zero pronoun can be said to be less grammatically odd as sentences with the demonstrative etot. The type (a) substitutions are expected to be the most frequent in younger children and with demonstratives and to disappear subsequently towards the older children. The type (b) substitutions are expected to be higher in younger children and in non-prototypical sentences, like, for example, condition B with inanimate subject and animate object. This type (b) is expected to be governed by the reverse mapping principle and by the fact that personal pronouns are the most neutral 'means of indicating continuity of reference across a sentence boundary' (Kresin 1998: 424) that do not switch the topic. I argue that the reverse mapping principle should be considered only for pronouns the anaphoric functions of which are not referentially restricted or contextually constraint; thus only a slight effect, if any at all, is expected with the demonstrative pronoun, the resolution of which undergoes the specific, con- 
textually dependent rules. Furthermore, this principle can be applied only in a limited degree to zero vs. personal pronouns and only with the older children. ${ }^{11}$ These two types of pronouns allow the broader referential choice, i.e. their anaphoric functions are 'under-specificated', in the target Russian. It is expected that animacy in the youngest children and a syntactic role in the oldest children will govern the referential choice of the erroneously repeated zero and personal pronouns. Thus, the following continua of preferences are predicted: with younger children [animate (subjects, objects) < inanimate (subjects, objects)] and with older children [subjects (animate, inanimate) $<$ objects (animate, inanimate)].

\subsection{Elicited imitation strategies - results}

Results will be presented in four sections. The first two sections give an overview of all children's responses to the stimuli sentences and all responses, containing pronouns (these latter responses will be the matter of analyses). The two concluding sections deal with errors in elicited imitation.

Figure 5 below shows that already the youngest children successfully participated in the experiment: almost $60 \%$ of them produced the results that were possible to evaluate for the purpose of the study.

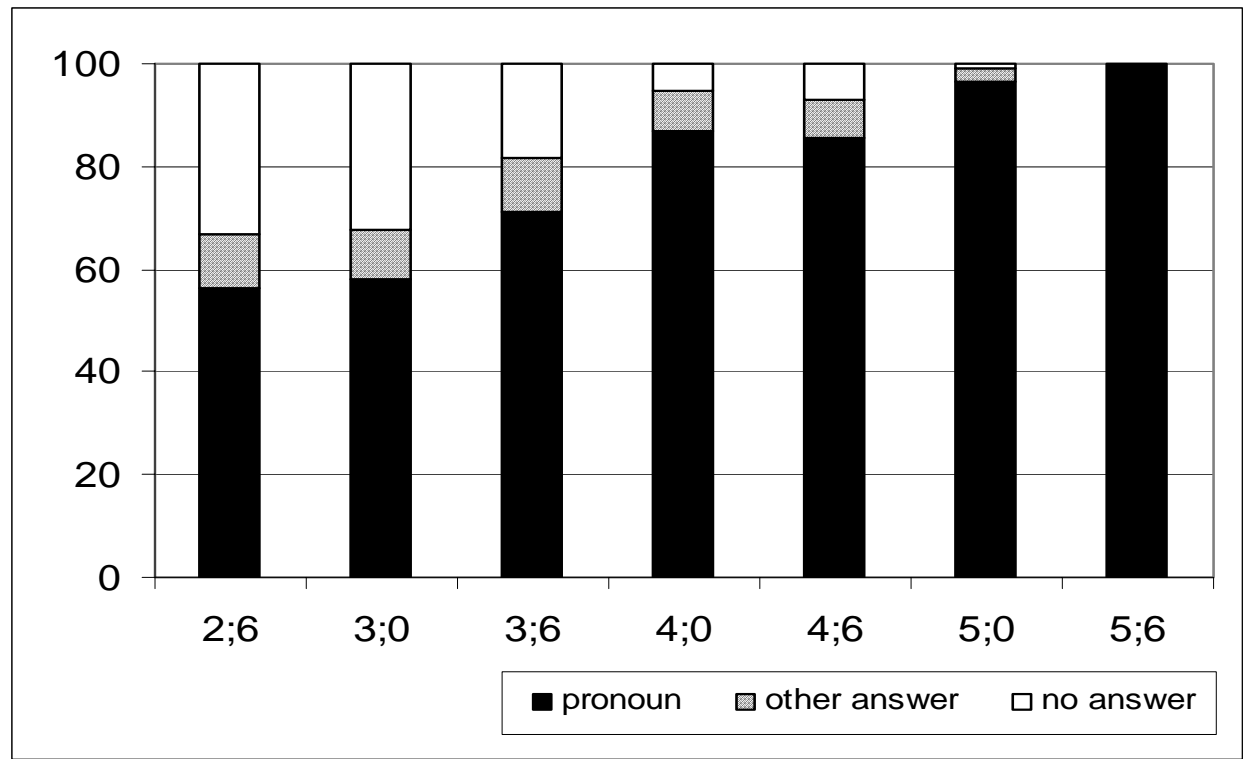

Figure 5: Overview of the elicited repetition

The next Figure 6, gives an overview of all sentences with personal, demonstrative or zero pronoun irrespectively of their correctness, i.e. whether they re-

11 Only the older children may show the establishment of the different anaphoric functions between the zero and personal pronoun. 
peated the target pronoun or substituted it. Figure 6 shows that children did not repeat automatically all stimuli (if they would have repeated everything without any changes, the distribution would have been similar for each type-33,33\%), but changed them in the way that the proportion of zero pronouns decreases with age and the proportion of personal pronouns increases.

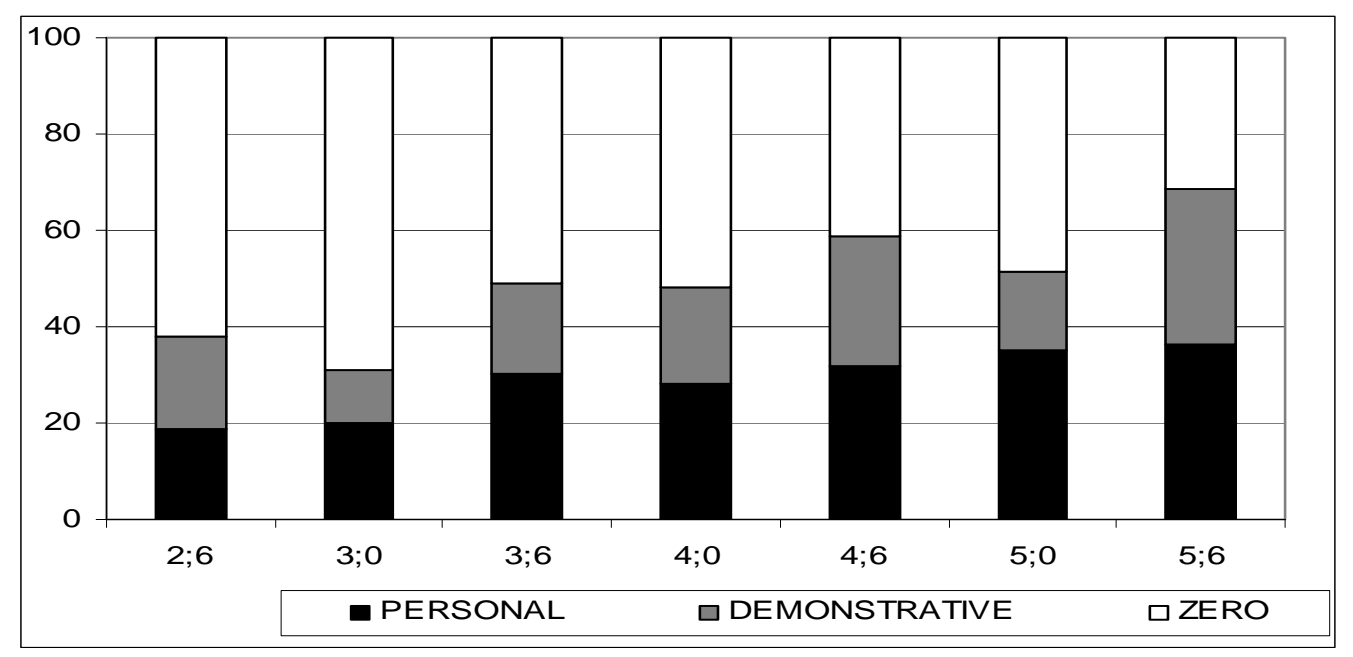

Figure 6: Overview of the repeated pronouns

The extraction of the erroneous uses of pronouns from all responses is the most important part of the elicited imitation experiment, see Figure 7 below.

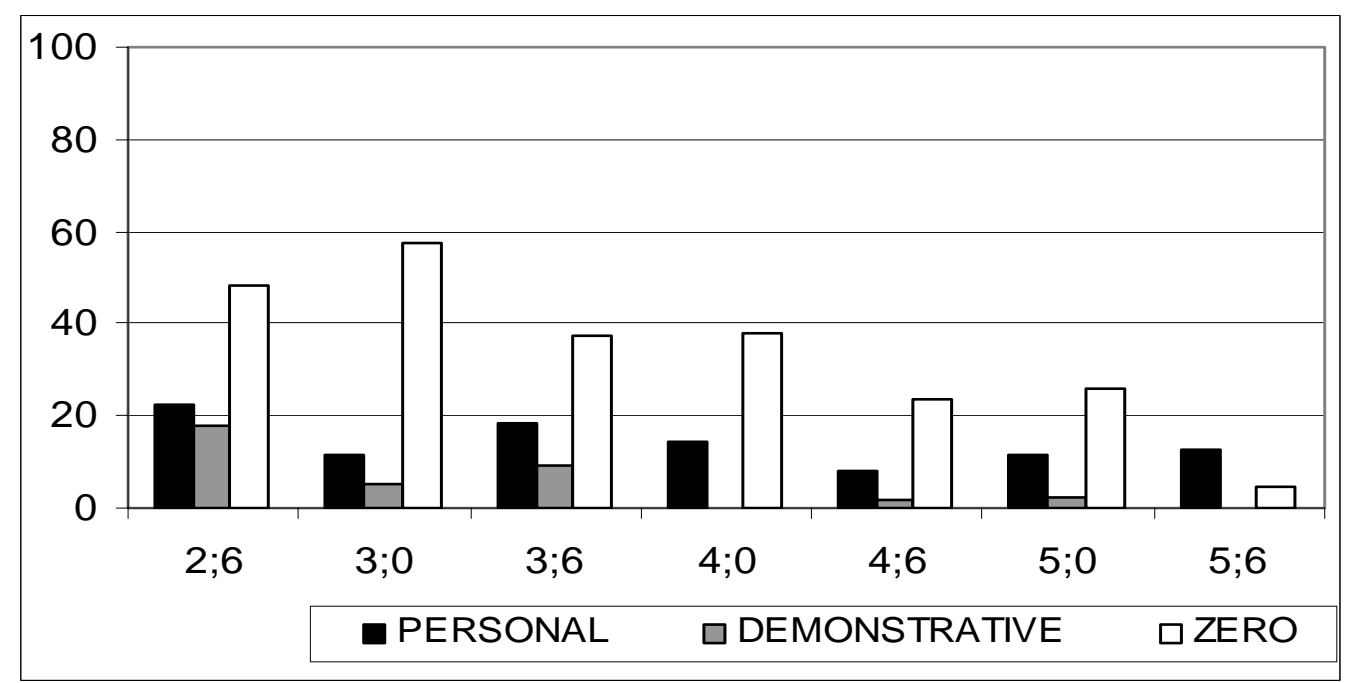

Figure 7: Erroneous repetitions of the pronouns

This figure demonstrates the steady decrease of the zero and demonstrative errors and the permanence (with a slight diminishment) of the personal pronouns. Thus, our prediction that children would more or less stably use personal pronouns as the substitution for the grammatically odd demonstratives and zeros holds. Further, as expected, the number of zero pronouns decreases with age (cf. 
Gerken 1991 and Valian et al. 1996 on the subject omission), i.e. children show a reduce in the omission of pronominal subjects.

Compare the conditions in which these substitutions occur, Figures $8 \mathrm{a}$ and $8 \mathrm{~b}$, which illustrates the numbers and the proportional distribution of pronouns. Note, that since the absolute numbers of the substitutions are relatively low and that only three groups are compared, the numbers of the two subgroups of each full year are summarised, e.g. three-year-olds are compiled from $3 ; 0$ and $3 ; 6$, etc.

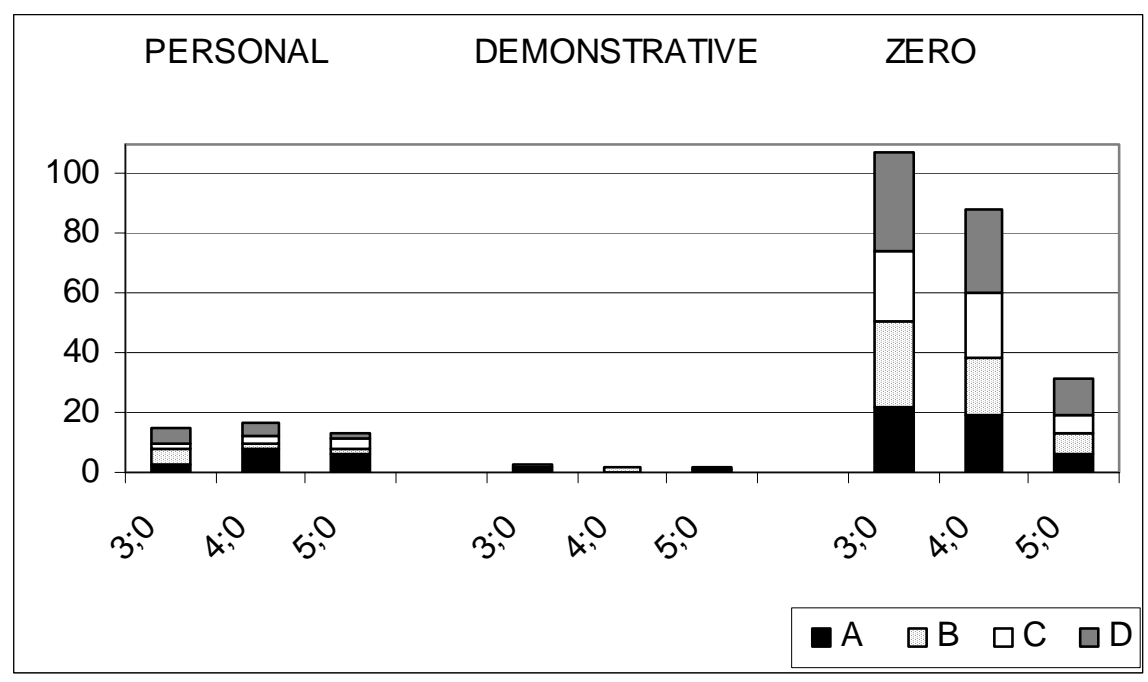

Figure 8a: Distribution of the erroneous repetitions of the pronouns: numbers

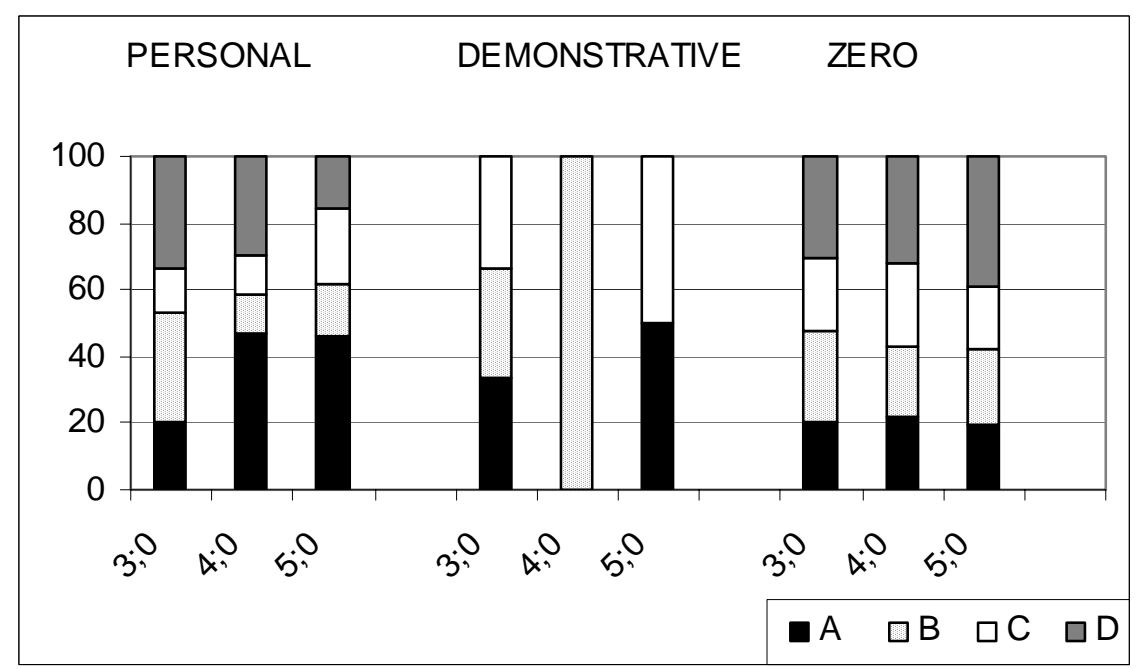

Figure 8b: Distribution of the erroneous repetitions of the pronouns: percentages

With personal pronouns two general tendencies are observed: the first tendency is the increase of substitutions in condition A towards the older children (remember the steady growth of subject choices in condition A towards older children). Thus, the most remarkable result at this point is the children's increasing 
substitution of demonstrative and zero pronouns with personal pronouns (in conditions $\mathrm{A}$ and $\mathrm{C}$, but not $\mathrm{B}$ and $\mathrm{D}$ ) parallel to the increasing choice of subjects. Do we have to interpret these two analogous tendencies as the acquisition of the syntactical role and establishment of the resolution rules of the anaphoric $3^{\text {rd }}$ person pronoun in discourse? Or as the establishment of pure resolution rules, in our case, the similarity rule?

The second tendency, is the modest but steady increase of substitutions in condition $\mathrm{C}$ towards the oldest group (remember the constant increases of subject choices and very slight decreases of object choices towards the older children in C). Again, is there any connection between the erroneous production of personal pronouns and subject choices? There is one more drop of substitutions in condition B after the age of 3;0 (no significant changes in the choice of subjects vs. objects in this condition across pronouns and groups). There is one more, modest but steady, increase of substitutions in condition B (remember no changes in subject vs. object preferences in B).

Demonstrative pronouns hardly are erroneously used to substitute the other pronouns in the target stimuli, hence they will not be treated.

Finally, zero pronouns absolutely dominate in all conditions at $3 ; 0$ and show a significant regression by $5 ; 0$. Across all conditions where zeros are only seldom used, condition D dominates.

The erroneous uses of zero and personal pronouns are compared with their antecedent's choices in the last figure, Figure 9.

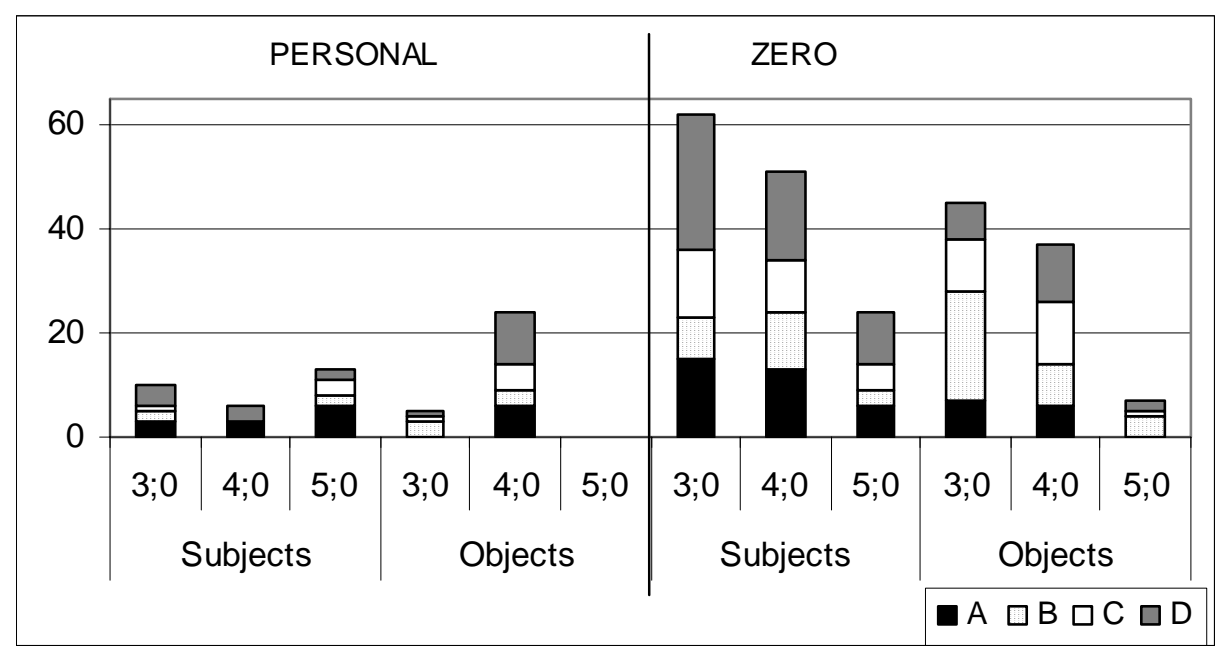

Figure 9: Resolution of the erroneously repeated personal and zero pronouns into subjects and objects (numbers) 
Figure 9 aims at showing the deliberately erroneous repetitions of anaphoric pronouns together with the resolution of these pronouns. It thus crowns the previous analyses in that it most strongly shows the interaction between (elicited) production and resolution of the anaphoric pronouns in Russian.

The production of personal pronouns with the subsequent choice of subjects or objects does not show an age-consistent picture for neither subjects nor objects. However, the choices of subjects preponderate in the youngest children, and these choices remain the only ones in the older children. The middle group seems to be at crossroad and restructuring its resolution strategy: the children of this group suddenly assign objects to the personal pronouns; and this effect is mostly seen in condition D. As far as the distribution of resolution strategies across the four conditions is concerned, condition A seems to be the most constant with the youngest and the oldest groups - it is in this condition that the children choose subjects, especially the oldest group.

To recapitulate, zero pronouns are used most often by the youngest children and their number decreases towards the oldest group. This is as expected, since the older children omit pronouns less frequently then the younger children (see Freundenthal et al. 2007). Furthermore, although zero pronominal subjects are admitted in the tested contexts/situations, they still sound odd despite the extralinguistic situations acted out. So, with zero pronouns children of all ages show a strong preference for subjects, this preference is mostly clear in the oldest children. This tendency is particularly evident in prototypical condition $\mathrm{D}$, in which the tandem of animacy and the syntactic role of subject promotes the resolution of zero pronouns onto subjects. Does this mean that already young children are sensitive to the syntactic role? The partial answer to this question can be found in the results for conditions A with the two animate antecedents and $\mathrm{C}$ with the two inanimate antecedents: the two verb arguments differ only in their syntactic role. Hence, if younger children are able to recognise the syntactic role (and rank it higher than the other antecedent's features) and the anaphoric 'force' of the zero pronouns, they should resolve them into subjects. This is what we observed in A, but not in C. Finally, in condition B, children predominantly choose animate objects.

\section{$5 \quad$ Discussion and conclusion}

The discussion and conclusion will be given in turn, corresponding to the parts 3.2. and 4.2.. To sum up part 3.2., the resolution of anaphoric pronouns in subject position is governed by the similarity rule: an overwhelming number of children choose subjects as antecedents. A closer look into the animacy and subjecthood of the antecedents and the type of anaphoric pronouns reveals various violations of this rule however. 
First, as was predicted, younger children, especially the two younger groups, prefer objects in sentences with inanimate subjects and animate objects (condition B), thus, they rank the animacy of a protagonist higher than the syntactic rule and they also place it over the similarity rule. Second, as it was also predicted, the preference for subjects as resolution candidates is much higher in the 'prototypical' sentences with animate subject and inanimate objects (condition D) since the contrast of the syntactic roles is strengthened by animacy. Third, in sentences with animate subjects and objects (A condition), children with age increasingly prefer subjects, i.e. the establishment of the dominance of a syntactic role is becoming more certain and definite. The same tendency, although a bit weaker, is seen in sentences with inanimate subjects and objects $(\mathrm{C}$ condition). Thus, in these two conditions, where the animacy of the protagonists does not differ, one may indirectly observe the establishment of the syntactic role. This establishment is manifested in that children are learning the prominence of subjects and choose them as the most probable antecedents of the subject anaphora.

Furthermore, the similarity rule is consequently overridden by adults in condition $\mathrm{C}$ across all pronouns and in all four conditions with demonstratives. As it has been mentioned in section 1.2., demonstratives constitute a pronominal class with specific anaphoric functions which are realised in a restricted set of contexts which were not the subject of this study. In the contexts that were used in the study, adults display the controversial contrive or 'against' strategy which may be strengthened by the recency of mentioning and/or topic shift effect. This strategy means that potentially considering subjects as the correct antecedents of the anaphora, they deliberately choose objects, assuming a counterfeit in the experiment. The topic shift effect may serve as an additional explanation for the strong preference for objects across all conditions with demonstratives - since this type of pronoun guides the topic shift (the 'marked' anaphoric reference), adults resolve it to objects even in the non-target conditions. That fact that adults resolve the anaphoric demonstrative etot into object speaks for the last, fourth prediction of section 3.1., namely that the similarity rule is pronoun-sensitive, since it maybe violated by restrictions in its anaphoric functions of some pronouns (see Russkaja Grammatika-80). Finally, while the domination of the similarity rule is generally corroborated by the results across four types of sentence conditions taken together with the older children, it overridden by a set of factors.

To sum up part 4.2., the children substitute the anaphoric pronouns in the elicited imitation task in the following manner: zero pronouns are used most frequently, followed by the personal pronouns; demonstrative are hardly ever produced and hence will not be treated below. When the children produce zero pronouns, they generally prefer subjects and not objects. The situation differs 
across conditions: the preference for subject is most clear in condition $\mathrm{D}$ - even the youngest group of children favour animate subjects. The preference for subjects is less clear in condition A, and most vague in condition C. All children preferably resolve the zero anaphora into the animate subjects, thus showing sensitivity to animacy. Remarkably, if the subject is used together with the inanimate object, then the preference rate is higher than with an animate object. However, in condition B, the youngest children definitely go for objects $(p<0,0157)$, and the older groups show a performance at chance level. The youngest children prefer animate antecedents - the summary of all conditions, except for $\mathrm{C}$, shows that irrespectively of the syntactic role they choose animate antecedents. Since the rate of the erroneous uses of personal pronouns is low, only restricted conclusions can be drawn.

The anaphoric system of the youngest group of Russian-speaking children can be said to consist of zero and personal pronouns without the clear division of functions within these two types of anaphora. This diffusion can be interpreted in terms of the structural peculiarities of the target system children acquire. In this target system, the personal pronouns are underspecified, and there is no clear <one form -- one function> relationship. Moreover, the zero pronouns also do not exhibit a clearly restricted and transparent (contextually deciphered) relationship to their antecedents. This situation is complicated by the processing work children have to perform in the anaphora resolution process.

The attempt to build the schema of the resolution rules depending on (a) the salience status of an antecedent and (b) the type of pronouns is presented in (6). This schema is a linear continuum - for the older children (four types of potential antecedents) - with the salience decreasing towards the right edge:

$$
\text { animate } \mathrm{S}>\text { inanimate } \mathrm{S}>\text { animate } \mathrm{O}>\text { inanimate } \mathrm{O}
$$

These four types of sentences build a somewhat different continuum of hierarchal salience if looking at younger children and if one treats the object and subject in tandem. Since younger children rely more strong on animacy, this continuum will have the following order, with the salience decreasing left-right:

animate $(\mathrm{S}, \mathrm{O})>$ inanimate $(\mathrm{S}, \mathrm{O})$

In (7), the notions of subject and object are not yet clearly 'governed' by the anaphoric functions of pronouns and are not yet established in the system of anaphoric reference. This establishment develops towards the group of the older children, which rank subjects higher and thus choose them as antecedents in conditions where the subject and objects exhibit a similar level of animacy. 
More research needs to be done in order to examine the establishment of the system of the anaphoric pronominal reference in children. This will be the subject task of the next set of experiments.

\section{References}

Adamec, P. (1988). K vyjadřování a rozpoznávání koreference c ruštine a češtině. Československá 1988: 167-177.

Ambridge, B. \& J. Pine (2007). Testing the Agreement/Tense Omission model using an elicited imitation paradigm. Journal of Child Language, 33: 879-898.

Ariel, M. (2001). Accessibility Theory: An Overview. In: T. Sanders, J. Schilperoord \& W. Spooren (eds.), Text Representation. Amsterdam, Philadelphia: Benjamins, 29-88.

Bamberg, M.G. (1987). The Acquisition of Narratives. Berlin, New York, Amsterdam: De Gruyter.

Bittner, D. (2002). Emergence of grammatical complexity and markedness in the acquisition of verb and noun phrases in German. In: K. Dziubalska-Kolaczyk \& J. Weckwerth (eds.), Future Challenges for Natural Linguistics. Wien: Lincom, 25-56.

Bittner, D. (2007). Early functions of definite determiners and DPs in German first language acquisition. In: Stark, Elisabeth, Elisabeth Leiss \& Werner Abraham (eds.), Nominal determination. Typology, context constraints and historical emergence. Amsterdam/ Philadelphia: Benjamins (Studies in Language Companion Series 89), 213-238.

Bosch, P., G. Katz \& C. Umbach. (to appear). The Non-Subject Bias of German Demonstrative Pronouns. In M. Schwarz-Friesel, M. Consten, M. Knees (eds), Anaphors in Texts Cognitive, formal and applied approaches to anaphoric reference, 145-164.

Brennan, S., M.W. Friedman \& C.J. Pollard (1987). A Centering Approach to Pronouns. Proceedings of the $25^{\text {th }}$ Annual Meeting of Association for Computational Linguistics, Stanford, 155-162.

Burzio, L. (1996). The Role of the Antecedent in Anaphoric Relations. In: R. Freidin (ed.), Current Issues in Comparative Grammar. Dordrecht: Kluwer.

Bussmann, H. (1996). Routledge Dictionary of Language and Linguistics. London, New York: Routledge.

Dale, P. \& C. Crain-Thompson (1993). Pronouns reveals: Who, when, and why? Journal of Child Language, 20:573-589.

Dobrova, G.R. (2003). Ontogeny of the Personal Dexis (personal pronouns and kinship terms). [Ontogenez personal'nogo deiksisa (lichnyje mestoimtnija i terminy rodstva)]. St. Peterburg: RGPU-Press.

Franks, S. (1995). Parameters of Slavic Morphosyntax. Oxford: Oxford University Press.

Gagarina, N. (2006). Pervyje mestoimenija v detskoj rechi (na materiale dannyh russkoj rechi dvuh detej: bilingva I monolingva). [Early pronouns in child speech: A comparison of two children: a Russian monolingual and a German-Russian bilingual]. Proceedings of the Conference on Language Development and Linguistic Education of Children, Orjol (Russia): Kartusch, 126-129.

Gagarina, N. \& I. Guelzow (2007). Anaphoric elements in discourse. Talk presented at the Workshop on the Information Structure in Adult and Child Language. 29-31 March 2007, MPI Nijmegen. 
Golinkoff, R.M., C.G. Harding, V. Carlson-Luden \& M.E. Sexton (1984). The infant's perception of causal events: The distinction between animate and inanimate objects. In L.P. Lipsitt (ed.), Advances in infancy research, 3. Norwood (NJ): Ablex, 145-151.

Grosz, B., S. Weinstein \& A. Joshi (1995). Centering a framework for modeling the local coherence of discourse. Computational linguistics, 21.2.

Gundel, J., N. Hedberg \& R. Zacharski (1993). Cognitive status and the form of referring expressions in discourse. Language, 69.2.

Haijčova, E., B. Partee \& P. Sgall (1993). Topic-Focus Articulation, Tripartite Structure and Semantic Content. Dordrech: Kluwer.

Hickmann, M. (2003). Children's discourse: Person, space and time across languages. Cambridge Studies in Linguistics, 98. Cambridge: Cambridge University Press.

Hickmann, M., M. Kail, \& F. Roland (1995). Cohesive anaphoric relations in French children's narratives as a function of mutual knowledge. First Language, 15: 277-300.

Huang, Y. (2000). Anaphora: A cross-linguistic study. Oxford: Oxford University Press.

Isacenko, A.V. (1968). Die Russische Sprache der Gegenwart. VEB Max Niemeyer Verlag.

Kail, M. (1976). Stratégie de compréhension des pronoms personnels chez le jeune enfant. Enfance, 3-4: 447-466.

Karmiloff-Smith, A. (1981). The grammatical marking of thematic structure in the development of language production. In: W. Deutsch (ed.), The child's construction of language. London: Academic Press, 121-147.

Karmiloff-Smith, A. (1980). Psychological process underlying pronominalization and nonpronominalization in children's connected discourse. In J. Kreiman \& A.E. Ojega (eds.) Papers from the parasession on pronouns and anaphora. Chicago: Chicago Linguistic Society.

Koktová, E. (1992). Anaphoric expressions across clause boundary in pro-drop languages. Prague Bulletin of Mathematical Linguistics, 58: 39-63.

Krasavina, O. (2004). Upotreblenije ukazatel'noj imennoj gruppy v russkom pis'mennom narrativonom diskurse. [The use of a demonstrative NP in Russian written narrative discourse. Issues in Linguistics] Voprosy jazykoznanija 3: 51-68.

Krasavina, O., C. Chiarcos \& D. Zalmanov (2007). Aspects of topicality in the use of demonstrative expressions in German, English and Russian. Proceedings of the 6th Discourse Anaphora and Anaphor Resolution Colloquium (DAARC-2007), Lagos (Portugal), March 29-30.

Kresin, S.C. (1998). Deixis and thematic hierarchies in Russian narrative prose. Journal of Pragmatics, 30: 421-435.

Levinson, S.C. (2000). Presumptive Meanings: The theory of generalized conversational Implicature. Cambridge (MA), London: MIT Press.

Lust, B. (1981). Constraint on anaphora in child language: A prediction for a universal. In: S. Tavakolian (ed.), Language acquisition and linguistic theory. MA, MIT Press, 74-96.

MacWhinney, B. (2000). The CHILDES project: tools for analyzing talk. Vol. I: Transcription, format and programs. Mahwah (NJ): Lawrence Erlbaum Associates.

Nicolova, R. (1986). Bulgarskite mestoimenija. [Bulgarian Pronouns] Sofia: Nauka i izkustvo.

O'Grady, W. (2005). How Children Learn Language. Cambridge: Cambridge University Press.

Paducheva, E. V. (1985). Vyskazyvanije i ego sootnesjonnost' s deistvitel'nost'ju (Referencial'nyje aspekty semantiki mestoimenij). Moskva, Nauka. 


\section{Natalia Gagarina}

Poulin-Dubois, D., A. Lepage \& Ferland, D. (1996). Infants' concept of animacy: Conceptual foundations for verb learning 38. Cognitive Development, 11: 19-36.

Reinhart, T. (1983). Anaphora and semantic interpretation. London: Croom Helm.

Revzin, I. (1973). Transformacionnoe issledovanie konstrukcij s sub"ektnym i ob"ektnym priimennym dopolneniem: Genitivus subjectivus i Genitivus objectivus". In A.A. Zaliznjak (ed.), Problemy grammatiãeskogo modelirovania. Moscow: Nauka, 88-95

Richard, M., P. Girouard \& T.G. Décarie (1999). Personal pronouns and perspective talking in tofflers. Journal of Child Language, 26: 681-697.

Rosental, D.E., I.B. Golub \& M.A. Telenkova (1991). Sovremennyj russkij jazyk. Moskva: Vysshaja Shkola.

Sasse, J. (2001). Recent Activity in the Theory of Aspect: Accomplishments, Achievements, or just Non-progressive State?. KLANN, Arbeitspapiere, 40. Köln.

Švedova et al. (1980). Russkaja Grammatika-80. Moskva.

Siegmüller, J. and C. Kautchke (2006). Patholinguistische Therapie bei Sprachentwicklungsstörungen. München: Urban \& Fischer.

Strube, M. \& U. Hahn (1999). Functional Centering: Grounding referential coherence in information structure. Computational Linguistics, 25.3: 309-344.

Voeikova, M. (2000). Existential Sentences. München: Lincom.

Wykes, T. (1981). Inference and children's comprehension of pronouns. Journal of Experimental Child Psychology, 32: 264-278.

\section{$7 \quad$ Appendix 1}

Fellow 1

\begin{tabular}{|c|c|c|}
\hline $\begin{array}{l}\text { Senten. } \\
\text { type }\end{array}$ & Type of subject & Type of object \\
\hline A & $\begin{array}{l}\text { Animate Subject } \\
\text { Hare }\end{array}$ & $\begin{array}{l}\text { Animate Objec } \\
\text { Lion }\end{array}$ \\
\hline B & $\begin{array}{l}\text { Inanimate Subject } \\
\text { Ball }\end{array}$ & $\begin{array}{l}\text { Animate Objec } \\
\text { Bear }\end{array}$ \\
\hline $\mathrm{C}$ & $\begin{array}{l}\text { Inanimate Subject } \\
\text { Bus } \\
\text { Tractor }\end{array}$ & $\begin{array}{l}\text { Inanimate Obj€ } \\
\text { Tractor } \\
\text { Bus } \\
\end{array}$ \\
\hline D & $\begin{array}{l}\text { Animate Subject } \\
\text { Elephant }\end{array}$ & $\begin{array}{l}\text { Inanimate Obj€ } \\
\text { Tractor }\end{array}$ \\
\hline
\end{tabular}

Fellow 2

\begin{tabular}{|cll|}
\hline $\begin{array}{l}\text { enten. } \\
\text { type }\end{array}$ & Type of subject & Type of object \\
\hline A & $\begin{array}{l}\text { Animate Subject } \\
\text { Lion }\end{array}$ & $\begin{array}{l}\text { Animate Object } \\
\text { Hare }\end{array}$ \\
\hline B & $\begin{array}{l}\text { Inanimate Subject } \\
\text { Tractor }\end{array}$ & $\begin{array}{l}\text { Animate Object } \\
\text { Elephant }\end{array}$ \\
\hline C & $\begin{array}{l}\text { Inanimate Subject } \\
\text { Scarf }\end{array}$ & $\begin{array}{l}\text { Inanimate Objec } \\
\text { Pencil }\end{array}$ \\
\hline D & $\begin{array}{l}\text { Animate Subject } \\
\text { Bear }\end{array}$ & $\begin{array}{l}\text { Inanimate Objec } \\
\text { Ball }\end{array}$ \\
\hline
\end{tabular}

